\title{
AVALIAÇÃO DOS PRINCIPAIS LIVROS DIDÁTICOS DE FILOSOFIA PARA O ENSINO MÉDIO EXISTENTES NO MERCADO EDITORIAL BRASILEIRO
}

\author{
Marcos de Camargo Von Zuben* \\ Joelson Silva de Araújo** \\ Izanete de Medeiros Costa***
}

RESUMO: Este artigo apresenta os resultados de pesquisa que teve como objetivo a avaliação de oito livros didáticos de filosofia para o ensino médio, selecionados como os principais livros disponíveis no mercado editorial brasileiro. Apresenta o referencial teórico sobre conteúdos e metodologias mais adequadas para o ensino de filosofia no nível médio, expõe a metodologia empregada para a análise dos livros e discute os resultados obtidos.

Palavras-Chave: livro didático; filosofia; ensino médio; avaliação; Brasil

RESUMEN: Este artículo presenta los resultados de las investigaciones destinadas a la evaluación de ocho libros de texto para la filosofía de la escuela secundaria, seleccionados como los libros más importantes disponibles en el mercado editorial brasileño. Presenta el marco teórico sobre el contenido y las metodologías más adecuadas para la enseñanza de la filosofía en la escuela secundaria, se explica la metodología utilizada para analizar los libros y se analizan los resultados obtenidos.

Palabras clave: libros de texto; filosofía; la escuela secundaria; evaluación; Brasil

\section{Introdução}

A avaliação do livro didático no Brasil é algo relativamente recente. Somente a partir de 1996, o Ministério da Educação - MEC vem realizando a avaliação de livros didáticos. Em 1938, tiveram início as políticas para livros didáticos. Neste ano, o país começa a romper com a política vigente até a época, que utilizava apenas livros produzidos no exterior. Também em 1938, cria-se a Comissão Nacional do Livro Didático - CNLD. Comissão esta que tem como objetivo

\footnotetext{
*Doutor em filosofia pela Unicamp - Professor adjunto da UERN - zuben@uol.com.br.

** Graduado em licenciatura em filosofia, pela UERN - ajoelsonphilosofia@hotmail.com

***:Graduada em licenciatura em filosofia, pela UERN - izanete.costa@ig.com.br
}

VON ZUBEN, Marcos Camargos; ARAÚJO, Joelson Silva de; COSTA, Izanete de Medeiros. Avaliação dos principais livros didáticos de filosofia para o ensino médio existentes no mercado editorial brasileiro. Revista Sul-Americana de Filosofia $e$ Educação. Número 20: maio-out/2013, p. 157-178. 
"estabelecer condições para produção, importação e utilização de livros didáticos" (SPOSITO e LUCA, 2004, p. 552). Após o golpe militar de 64, surgem novas políticas voltadas para a educação. Em 1966, surge a Comissão do Livro Técnico e Didático - Colted. Essa comissão visava coordenar a produção, edição e distribuição de livros didáticos. Com a criação da Colted, o Estado assume a produção dos didáticos e desvincula-se das compras realizadas no exterior. Um dos motivos que levaram à criação da Colted foi a intensificação do êxodo rural na década de 1960. Com o significativo aumento da população urbana, fez-se necessário a ampliação das oportunidades de escolarização. Diante do aumento do número de vagas nas escolas, os livros didáticos passaram a ser produzidos em larga escala para atender à demanda. Isso acarretou a necessidade de uma comissão que coordenasse tal produção. Em 1970, com a crise internacional do capitalismo, houve um corte de verbas para o Brasil. Surge então a necessidade de uma melhor administração das verbas destinadas à educação. É criado o Instituto Nacional de Livro Didático - INLD, com a função de administrar e gerenciar os recursos financeiros nacionais e estaduais destinados às políticas educacionais. $\mathrm{Na}$ década de 1980 é criada a Fundação de Assistência ao Estudante - FAE com o objetivo de examinar os problemas existentes nos livros didáticos. A partir da criação da FAE os professores passam a participar da escolha dos livros. Com o aumento desta participação começa a surgir o Programa Nacional do Livro Didático - PNLD que se consolida apenas em 1993. Em 1996, tem início a avaliação dos livros didáticos no Brasil.

No mesmo ano é realizada a $1^{\text {a }}$ avaliação dos livros Didáticos no Brasil, sendo avaliados livros de Língua Portuguesa, Matemática, Ciências, Estudos Sociais, Geografia e História. De início, apenas dois critérios são considerados na avaliação: “a) não expressar preconceitos ou formas de discriminação e b) não conter erros ou não induzir a erros." (SPOSITO e LUCA, 2004, p. 557). Em 1998, surge outro critério: "Os livros didáticos não poderiam estar desatualizados" (SPOSITO e LUCA, 2004, p. 557). Com o passar do tempo e o melhoramento dos sistemas de avaliação, surgem novos critérios. A título de exemplo, cita-se a avaliação realizada pela UNESP com livros de geografia. Nesta avaliação foram 
levados em conta os critérios definidos pelo PNLD e os princípios gerais da Geografia. Os critérios classificatórios foram: a) aspectos teórico-metodológicos, entre eles: isenção de lacunas nos conteúdos e nas abordagens, ausência de estereótipos, presença de conceitos aceitos pela comunidade científica; b) Construção da cidadania; c) estrutura editorial; d) aspectos visuais; e) manual do professor.

$\mathrm{Na}$ área da filosofia, os estudos sobre livros didáticos ainda estão no início. A filosofia enquanto disciplina, ficou longe dos currículos escolares durante muito tempo. Ela volta às escolas por meio da aprovação da Lei n. 11.684/08, que modifica o Art. 36 da Lei 9.394/96 e que obriga os estados a incluírem filosofia como disciplina obrigatória nos currículos de ensino médio.

Com a volta da filosofia às escolas, surge a necessidade de um material didático adequado ao seu ensino. As editoras vêm lançando no mercado editorial brasileiro livros didáticos de filosofia que, em sua maioria, não foram objetos de avaliação. Sem que haja uma avaliação adequada dos livros didáticos, as escolas correm o risco de adotar livros que não se apresentam como instrumentos eficazes de ensino. É preciso avaliar os didáticos de filosofia para potencializar seu ensino. No Brasil não existem pesquisas específicas de avaliação de livros didáticos de filosofia ${ }^{1}$.

Assim, a presente pesquisa, pioneira nesta área, tem como objetivo avaliar os principais livros didáticos de filosofia do ensino médio existentes no mercado editorial brasileiro. Para realizar a avaliação definiram-se os componentes dos livros a serem avaliados, os critérios de avaliação e seus respectivos indicadores. $\mathrm{O}$ que se pretende com a investigação é apontar as limitações presentes nos livros didáticos de filosofia do ensino médio. Devido à escassez de fontes de pesquisa

1 Recebemos com satisfação a publicação da edição MEC Guia de livros didáticos PNLD/2012FILOSOFIA que visa orientar a escolha do livro de filosofia para o ensino médio a ser definido pelos professores da rede pública de ensino, com distribuição prevista para 2012. A definição dos três livros que foram considerados adequados para escolha dos professores passou por criteriosa avaliação de um especializado grupo de professores, como mostra o texto publicado. Há que se destacar que em razão dos objetivos dessa publicação, não se tratou de analisar mais detalhadamente todos os livros, mas indicar aqueles que não possuíam nenhuma restrição em relação aos critérios estabelecidos como padrão mínimo de qualidade. De modo diferente, a pesquisa que aqui é apresentada, finalizada em julho de 2010, tem como objetivo avaliar os problemas e as limitações dos livros didáticos. 
relativas à avaliação de livros didáticos de filosofia, tomou-se por base pesquisas realizadas em áreas correlatas. A pesquisa está fundamentada nos documentos oficiais e na vasta bibliografia que se tem produzido sobre a filosofia e seu ensino.

\section{A definição dos critérios e indicadores: o referencial teórico}

Esta pesquisa selecionou os seguintes componentes a serem avaliados no livro didático: conteúdos, metodologias/didática e conjunto gráfico. Definiram-se os seguintes critérios para a avaliação do componente conteúdo do livro didático de filosofia: a história da filosofia, as áreas fundamentais de investigação filosófica, os problemas filosóficos, léxico de filosofia, interdisciplinaridade e perspectiva filosófica. O componente metodologia/didática é composto de dois critérios: relação entre conteúdo filosófico e senso comum e atividades práticas. $O$ componente conjunto gráfico foi avaliado através dos critérios editoração $e$ aspectos visuais, e imagens e aspectos visuais.

Em um livro didático de filosofia podem surgir diferentes abordagens conteudinais. Os conteúdos de filosofia podem ser apresentados por meio de uma abordagem das áreas filosóficas, problemática ou histórica.

Em um ensino de filosofia, centrado unicamente na história da filosofia, o conteúdo das aulas é a produção filosófica, que pode ser transmitida centrando-se nos filósofos ou teorias filosóficas. Este tipo de abordagem de conteúdos, desvinculada de problemas, tende a tornar-se enciclopédico, "é um ensino de filosofia que podemos chamar de enciclopédico, e que não tem muita relação com o cotidiano de jovens estudantes." (GALLO e KOHAN, 2000, p.178), não há questionamento da tradição filosófica. Os conteúdos são transmitidos de forma repetitiva, tal qual foram pensados. Falta pensamento crítico e reflexivo. Assim, as aulas passam de aulas de filosofia a aulas de história da filosofia.

A abordagem baseada em problemas dá ênfase a questões que permeiam a filosofia ou a problemáticas atuais, entretanto,

Alguns professores desta vertente convidam os seus alunos para participar da escolha dos problemas de seu curso. $\mathrm{Na}$ maioria dos casos os alunos escolhem problemas de seu interesse imediato, como AIDS, drogas ou a vida após a morte, questões que muitos dos filósofos contemporâneos 
não aceitariam como problemas genuinamente filosóficos. (GALLO e KOHAN, 2000, p.178)

Muitas vezes, os problemas trabalhados de forma desvinculada da história da filosofia produzem reflexões que não saem do senso comum. As aulas limitam-se ao "achismo", os alunos apenas expressam suas opiniões sem levar em conta os pensamentos filosóficos e sua contextualização histórica.

Assim, a maneira mais apropriada de trabalhar os conteúdos é a que contempla as três abordagens citadas, com ênfase na história da filosofia. Essa abordagem é defendida pelos Parâmetros Curriculares Nacionais - PCN e Orientações Curriculares Nacionais - OCN. Um livro didático de filosofia que apresenta uma abordagem temática, problemática ou das áreas filosóficas, sem fazer menção à história da filosofia, conduz a um discurso vazio e improdutivo $e$ não à filosofia. Não se constrói um pensamento filosófico sem o alicerce que é a sua história, a tradição filosófica. Só se constrói filosofia a partir da filosofia.

Sendo evidente que o filosofar não se produz no vácuo, mas se desenvolve a partir de conteúdos concretos, vale dizer, sobre textos e discursos concretos, uma primeira escolha se impõe: não é possível pretender que o aluno construa uma competência de leitura filosófica sem que ele se familiarize com o universo específico em que esta atividade se desenvolve, sem que ele se aproprie de um quadro referencial a partir dos conceitos, temas, problemas $e$ métodos conforme elaborado a partir da própria tradição filosófica. (PCN, 1999, p. 335)

É impossível pensar um ensino de filosofia em que a sua história não ocupe lugar de destaque. A filosofia é um diálogo com a tradição. O seu conteúdo é discussão realizada ao longo de toda a tradição filosófica.

Não é possível fazer filosofia sem recorrer a sua própria história. Dizer que se pode ensinar filosofia apenas pedindo que os alunos pensem e reflitam sobre os problemas que os afligem ou que mais preocupam o homem moderno sem oferecer-lhe a base teórica para aprofundamento $e$ a compreensão de tais problemas e sem recorrer à base histórica da reflexão em tais questões é o mesmo que numa aula de física pedir que os alunos descubram por si mesmos a fórmula da lei da gravitação sem estudar Física, esquecendo-se de todas as conquistas anteriores naquele campo, esquecendo-se do esforço e do trabalho 
monumental de Newton. (NASCIMENTO, apud, OCN, 2002, p.27)

Dessa forma, na elaboração dos indicadores, no componente conteúdo, para que esse aspecto não seja negligenciado, consta que o livro deve contemplar todos os períodos da história da filosofia, de modo que o aluno perceba como o pensamento filosófico desenvolveu-se ao logo da história, bem como o contexto em que ele foi produzido.

Outro indicador explicita a importância da presença de textos clássicos nos livros didáticos de filosofia. O texto clássico proporciona o contato direto com a tradição filosófica:

O elemento material essencial ao qual a história da filosofia se refere é o texto, os escritos de um autor clássico. Por isso a história da filosofia se define fundamentalmente como lectio, lição, leitura. (CORNELLI, 2004, p.191)

Além de contemplar a história da filosofia, entre os indicadores consta que o livro deve apresentar os principais problemas filosóficos de modo a favorecer a reflexão e a compreensão de sua atualidade. Os problemas são essenciais para o desenvolvimento do pensamento reflexivo. Os problemas filosóficos estão intimamente ligados às experiências daqueles que os desenvolveram, pois toda filosofia nasce na tentativa de resolver um problema.

O problema não é uma operação puramente racional, mas parte do sensível; a experiência problemática é sentida, vivenciada, para que possa ser racionalmente equacionada como problema. Por isso o problema é sempre fruto de um encontro; há um encontro, uma experiência que coloca em relação elementos distintos e que geram problemática. E se o problema é o que força a pensar, somos levados a admitir que o princípio (origem) do pensamento é sempre uma experiência sensível. (GALLO, 2008, p. 118)

Pensados os problemas filosóficos, os alunos são levados a refletir sobre suas próprias existências e sobre o mundo atual, o que se procurou contemplar com esse indicador.

Na definição das áreas do conhecimento filosófico que devem estar presentes no livro didático, optou-se por separar aqueles conhecimentos que compõem o que se poderia chamar de "núcleo duro", ou conteúdos centrais da filosofia em um 
item específico, que são a ontologia, teoria do conhecimento, lógica, ética e filosofia política; observe-se que a importância central desse conteúdo mínimo é também atestada nos PCN+ (2006, p.52-53) e OCN (2002, p.34-35) de filosofia, os quais, por sua importância, não podem faltar em qualquer livro didático. Em item separado, relacionaram-se outras áreas em que se pretende avaliar se o livro amplia os conteúdos para além do mínimo exigido.

Outro importante indicador, contemplado dentro do critério conteúdo, se refere ao item perspectiva filosófica. Aqui, pretende-se avaliar o aspecto do livro relativo ao posicionamento filosófico do autor e em que medida ele se abre ao diálogo e ao confronto crítico com outras perspectivas presentes na tradição do pensamento. O reconhecimento da diversidade de perspectivas filosóficas presentes ao longo da tradição, inclusive na atualidade, deve ser reconhecido $e$ incorporado como elemento importante na estruturação do livro didático, incluindo o fato de o próprio autor do livro didático se conduzir inexoravelmente para alguma perspectiva determinada ao elaborar seu livro. Segundo Marcondes (2004, p. 57)

A história da filosofia nos revela, contudo, que ao longo dessa tradição não houve uma única linha predominante de pensamento, e nem um estilo único de se fazer filosofia. A filosofia desenvolveu-se através de aproximações em maior ou menor grau com a ciência natural, a matemática, a arte, a política, a religião e o mito.

A presença de diversidade e coexistência de perspectivas filosóficas diferentes se relaciona com a preocupação de que o livro didático não se torne algo dissimulado, dogmático e doutrinário, desconsiderando o fato de que sempre se está em alguma posição filosófica e em relação de semelhanças ou diferenças com outras linhas do pensamento filosófico, e que suas próprias posições devem, também, se colocar sob a atitude crítica inerente a todo filosofar. Assim vemos presente nas OCN (2002, p. 18) que se deve evitar posições

Doutrinárias que terminam por roubar à filosofia um de seus aspectos mais ricos, a saber, a multiplicidade de perspectivas, que não deve ser reduzida a uma voz unilateral. Mostrou-se, pois, necessária uma reformulação que evite imposições doutrinárias, mesmo quando resultante das melhores intenções. Um currículo de filosofia deve 
contemplar a diversidade sem desconsiderar o professor que tem suas posições, nem impedir que ele as defenda.

Por fim, quanto ao critério conteúdo, foi incluído também um indicador relativo à interdisciplinaridade, visto esta se relacionar com as próprias características da filosofia que, por sua natureza, se faz em um encontro essencial com outras áreas do saber, seja voltando-se sobre elas, seja alimentando-se delas para o seu próprio desenvolvimento. Conforme os Parâmetros Curriculares Nacionais - PCN a resolução 03/98, no $\S 2^{\circ}$ aponta para esta natureza da filosofia.

As propostas pedagógicas das escolas deverão assegurar tratamento interdisciplinar e contextualizado para os conhecimentos de filosofia. Assim o papel da filosofia fica alargado e poderemos, a partir de qualquer posição em que estivermos, ajudar a pôr em marcha a cooperação entre as diferentes perspectivas teóricas e pedagógicas que compreende o universo escolar. (PCN, 1999, p 329)

Também nos $P C N+(2006$, p.44) este caráter interdisciplinar é reafirmado.

Pela sua especificidade, a filosofia: abre o espaço por excelência para tematizar e explicitar os conceitos que permeiam todas as outras disciplinas, e o faz de forma radical, ou seja, buscando suas raízes ou fundamentos $e$ pressupostos; ['] examina os problemas sob a perspectiva de conjunto enquanto as ciências particulares abordam "recortes" da realidade - o que permite à filosofia elaborar uma visão globalizante, interdisciplinar ["'] não trata de um objeto específico, como nas ciências, porque nada escapa ao seu interesse, ocupando-se de tudo.

Assim, na medida em que lida com conceitos, e que estes conceitos estão presentes em todas as disciplinas, a filosofia rompe as barreiras que as separam $e$ cria a possibilidade de tornar o ensino interdisciplinar, aspecto que deve, portanto, estar presente na organização do livro didático de filosofia.

Com relação ao componente metodologia/didática de ensino, temos como um dos indicadores que o livro deve ser organizado de tal maneira que propicie a apreensão de seu conteúdo de modo significativo pelos estudantes. No caso da filosofia, tornar um conteúdo significativo se refere, em primeiro lugar, ao questionamento, pelos estudantes, dos valores e das atitudes que constituem o senso comum de uma dada sociedade ou cultura, de modo a perceber a relevância em adentrar no universo dos problemas propriamente filosóficos e no 
conhecimento das diversas respostas apresentadas a eles ao longo da tradição filosófica. Segundo Souza (2004, p. 170)

Todos os adolescentes têm, em grau mais ou menos consciente, uma concepção geral do mundo, das mudanças e transformações que nele e nas coisas se operam, de sua estabilidade e permanência dos seres e de sua capacidade de conhecer, enfim, da realidade e da existência. Assim, a ruptura com o modo cotidiano de perceber o real parece ser a porta principal pela qual se pode fazer o aluno ingressar na filosofia.

Assim, contemplou-se o indicador, para a avaliação do livro didático de filosofia, que verifica se a atitude crítica diante do senso comum está sendo possibilitada quando do tratamento dos diversos conteúdos ao longo do livro.

Ainda no componente metodologia, no critério atividades práticas, buscou-se abranger as competências e habilidades que o ensino de filosofia deve desenvolver nos alunos. Estas competências e habilidades estão expressas nos PCN. O livro didático de filosofia deve conter atividades e exercícios que propiciem a análise e interpretação de textos de natureza filosófica e de outras naturezas, bem como exercícios que estabeleçam a relação entre a filosofia e a vida cotidiana. Esse tipo de exercício busca desenvolver competências e habilidades de representação $e$ comunicação, a saber, "ler textos filosóficos de modo significativo" e "ler, de modo filosófico, textos de diferentes estruturas e registros" (PCN, 1999, p. 349). O exercício deve contemplar, ainda, a produção de textos filosóficos nos quais os alunos possam explicitar opiniões e discussões de forma reflexiva, desenvolvendo assim a habilidade de "elaborar por escrito o que foi apropriado de modo reflexivo" (PCN, 1999, p.349). Para desenvolver a competência de "debater, tomando uma posição, defendendo-a argumentativamente e mudando de posição em face de argumentos mais consistentes" (PCN, 1999, p. 349) é necessário que o exercício favoreça o debate e a argumentação sobre os textos, temas e problemas filosóficos abordados em detrimento da simples reprodução de conteúdos. Deve-se observar ainda, que o favorecimento do desenvolvimento das habilidades $e$ competências próprias à filosofia também estão presentes, ainda que de modo menos preponderante, em outros critérios a serem avaliados no livro didático, 
como a interdisciplinaridade e a relação entre conteúdos filosóficos e de senso comum.

Com relação ao componente conjunto gráfico, tomou-se como referência principal o contido no PNLD/2008 - Plano Nacional do Livro Didático, do Ministério da Educação, que fixa os critérios para a avaliação dos livros didáticos a serem adquiridos pelo Estado para as escolas públicas do país. Em razão de o Estado não adquirir livros de filosofia até quando se realizou esta pesquisa, considerou-se como referência mais próxima os critérios estabelecidos para os livros de história, adaptando-os ao livro didático de filosofia. Dentro do componente conjunto gráfico, indicou-se o critério de editoração, composto da apresentação e organização gráfica, textos e ilustrações, e normas técnicas de publicação, além do critério imagens e aspectos visuais. Dado o caráter técnico e geral deste componente, decidiu-se seguir o determinado no PNLD/2008 (2007, p. 16).

\section{Metodologia de avaliação}

O universo da pesquisa foi estabelecido a partir do critério de que o livro existente no mercado editorial brasileiro deveria, claramente, se propor a ser um livro didático para estudantes do ensino médio, objeto da presente investigação. Assim, livros que se propusessem a ser de iniciação à filosofia, mas que não se voltavam diretamente para o ensino médio foram excluídos da escolha. Foram oito os livros definidos como universo da pesquisa, considerados como os principais livros de ensino médio de filosofia de todo o país:

ARANHA, Maria Lúcia de Arruda; MARTINS, Maria Helena Pires. Filosofando:

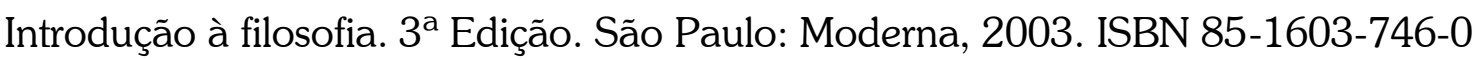

CHAUI, Marilena. Filosofia: ensino médio, volume único. São Paulo: Ática, 2005. Série Brasil. ISBN 85-08-09827-8.

CORDI, Cassiano et al. Para filosofar. 5 ed. São Paulo: Scipione, 2007. ISBN 978852626704-6.

SOUZA, Sonia Maria Ribeiro de. Um outro olhar: filosofia. São Paulo: FTD, 1995. ISBN 85-322-2439-3. 
SÁTIRO, Angélica; WUENSCH, Ana Mírian. Pensando Melhor: iniciação ao filosofar. $4^{a}$ edição reformulada. São Paulo: Saraiva, 2003. ISBN 85-0204-458-3,

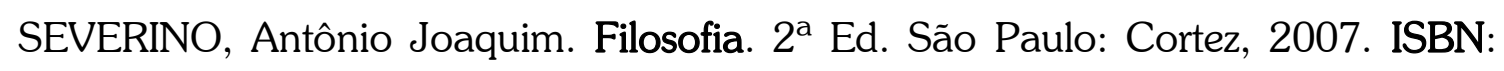
978-85-249-0410-3

COTRIM, Gilberto. Fundamentos da Filosofia: História e grandes temas. 16 ${ }^{\mathrm{a}} \mathrm{Ed}$. São Paulo: Saraiva, 2006. ISBN. 978-85-02-05787-6

CHALITA, Gabriel. Vivendo a Filosofia. $3^{\text {a }}$ Ed. São Paulo: Ática, 2009. ISBN: $978-$ 850810566-3.

Quanto à metodologia de avaliação, também se seguiu o determinado no PNLD/2008 (2007, p. 16), por entender que ele estabelece um modo de avaliação apropriado para os objetivos estabelecidos no âmbito da presente pesquisa, que são avaliar $e$ indicar as limitações presentes nos livros didáticos de filosofia existentes no mercado editorial brasileiro, na medida em que aponta a não aprovação daqueles indicadores que não observem os padrões mínimos estabelecidos pelos critérios aqui elencados, com o conceito Não e a aprovação de modo escalonado através dos conceitos Ótimo (quando atingisse plenamente o que estivesse estabelecido), Bom (quando alcançasse o que estava previsto em quase todos os pontos do item) e Suficiente (quando conseguisse apenas em parte ou de forma mínima o que fosse exigido).

Tomando-se por base os objetivos da presente investigação, buscou-se ao longo de toda a pesquisa indicar as limitações presentes em cada livro didático avaliado. Para tal efeito, a discussão dos resultados será voltada para a análise e descrição dos aspectos menos favoráveis da avaliação. Serão considerados como avaliações não favoráveis os critérios "suficiente" e "não". Cada livro foi considerado "suficiente" nos indicadores do instrumento de avaliação, quando atingiu apenas em parte, ou de forma mínima, o que foi exigido. Foi considerado "não" quando não atendeu ao mínimo necessário para se considerar o ponto avaliado, ou ainda, inexistente o componente solicitado. O "não" é considerado negativo por não corresponder ao exigido. O "suficiente" é considerado negativo porque, embora contemple de forma suficiente o exigido no item, necessita ainda importantes aperfeiçoamentos. 
Os pontos desfavoráveis serão apontados de três maneiras. Inicialmente serão citadas as limitações presentes nos componentes considerando todos os livros em conjunto. Em seguida, serão apresentados os indicadores que apresentaram maiores problemas. Tais procedimentos visam possibilitar uma avaliação de conjunto sobre quais componentes e indicadores têm apresentado maiores limitações dentre todas as publicações investigadas. Por último, serão apontadas as limitações de cada obra individualmente.

\section{O instrumento de pesquisa}

O instrumento de avaliação (abaixo) é composto por três componentes: conteúdo, metodologia/didática e conjunto gráfico, pelos respectivos critérios e por 21 indicadores que os avaliam. Foi solicitado que cada avaliador apresentasse sumariamente a justificativa para cada indicador avaliado.

\section{COMPONENTE: CONTEÚDOS}

\section{Critério: História da Filosofia.}

1. O livro contempla todos os períodos da história da filosofia (antiga, medieval, moderna e contemporânea) de modo a possibilitar o conhecimento do desenvolvimento histórico do pensamento filosófico ocidental.

\begin{tabular}{|l|l|l|l|l|l|}
\hline & Ótimo & Bom & Suficiente & Não \\
\hline
\end{tabular}

2. O livro apresenta os conteúdos filosóficos articulados em seus contextos históricos, geográficos e sociais, favorecendo a compreensão da relação entre o pensamento filosófico e seu contexto de produção; inclui dados biográficos e bibliográficos dos filósofos.

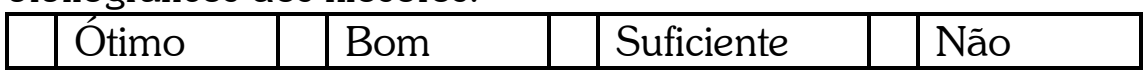

3. O livro apresenta os principais problemas, temáticas e perspectivas filosóficas presentes em cada período da história da filosofia.

\begin{tabular}{|c|c|c|c|}
\hline Ótimo & Bom & Suficiente & Não \\
\hline
\end{tabular}

4. O livro apresenta relações de influência, continuidade, diferença e descontinuidade entre as perspectivas filosóficas ao longo da história.

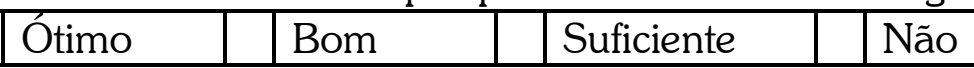

5. O livro apresenta textos clássicos da história da filosofia de modo a propiciar o contato direto com a tradição do pensamento filosófico.

\begin{tabular}{|c|c|c|c|}
\hline Ótimo & Bom & Suficiente & Não \\
\hline
\end{tabular}




\section{Critério: Áreas do Conhecimento Filosófico}

6. O livro aborda as diversas áreas temáticas da filosofia: ontologia, teoria do conhecimento, lógica, ética, filosofia política de modo a favorecer a compreensão de seus respectivos problemas, conceitos e teorias.

\begin{tabular}{|l|l|l|l|l|l|}
\hline & Ótimo & & Bom & Suficiente & Não \\
\hline
\end{tabular}

7. O livro aborda outras áreas do conhecimento filosófico, contemplando ao menos uma delas, tais como a filosofia da religião, bioética, filosofia da mente, filosofia das ciências humanas, estética, etc., de modo a favorecer a compreensão de seus respectivos problemas, conceitos e teorias.

\begin{tabular}{|l|l|l|l|l|}
\hline & Ótimo & Bom & Suficiente & Não \\
\hline
\end{tabular}

\section{Critério: Problemas Filosóficos}

8. O livro apresenta os principais problemas filosóficos de modo a favorecer a reflexão e a compreensão de sua atualidade.

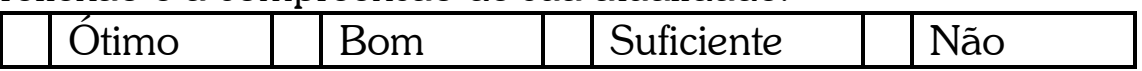

\section{Critério: Léxico de filosofia.}

9. O livro apresenta ao final de cada capítulo um léxico explicativo dos principais conceitos abordados, de modo claro e acessível, favorecendo a compreensão dos termos específicos da filosofia.

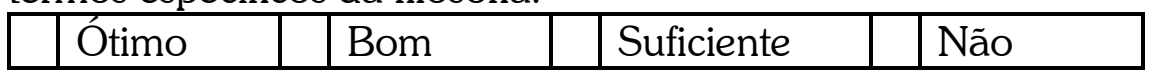

\section{Critério: Interdisciplinaridade}

10. O livro apresenta uma perspectiva interdisciplinar onde os conteúdos de duas ou mais disciplinas se relacionam integralmente, colocando em contato diferentes especialidades, de modo a articular uma visão de conjunto da realidade, permitindo o domínio significativo dos saberes.

\begin{tabular}{|l|l|l|l|l|}
\hline \hline & Ótimo & Bom & Suficiente & Não \\
\hline
\end{tabular}

\section{Critério: Perspectiva Filosófica}

11. O livro apresenta uma perspectiva filosófica definida, explicitando seus pressupostos, princípios e modo de compreensão próprio sobre os temas e problemas abordados, favorecendo a compreensão de que existem perspectivas filosóficas diversas, através da apresentação de respostas diferentes dadas a um mesmo problema, favorecendo o confronto crítico entre elas.

\begin{tabular}{|l|l|l|l|l|}
\hline & Ótimo & Bom & Suficiente & Não \\
\hline
\end{tabular}

\section{COMPONENTE: METODOLOGIA/DIDÁTICA.}

Critério: Relação entre conteúdo filosófico e senso comum. 
12. O livro proporciona a atitude crítica e distanciada das idéias e valores do senso comum, estabelecendo relações entre os problemas filosóficos e os problemas cotidianos de modo em que o pensamento filosófico sirva de referência para se pensar criticamente os problemas e as produções culturais da vida contemporânea.

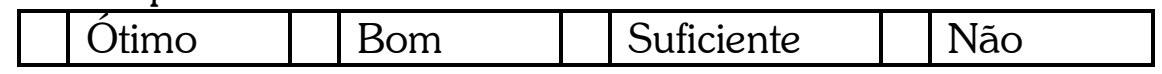

\section{Critério: Atividades Práticas.}

13. O livro apresenta exercícios e atividades que contemplem análise e interpretação dos textos filosóficos, e textos de outra natureza, favorecendo o desenvolvimento da competência de análise e interpretação.

\begin{tabular}{|l|l|l|l|l|}
\hline & Ótimo & Bom & Suficiente & Não \\
\hline
\end{tabular}

14. Presença de exercícios que contemplem a produção de textos filosóficos, que incitem o aluno a redigir textos explicitando opiniões, discussões, considerando como uma forma de recapitular e expandir o conteúdo estudado.

\begin{tabular}{|l|l|l|l|l|}
\hline & Ótimo & Bom & Suficiente & Não \\
\hline
\end{tabular}

15. O livro apresenta atividades e exercícios que favoreçam o debate e a argumentação sobre os textos, temas e problemas filosóficos abordados.

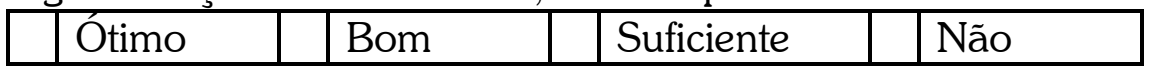

16. O livro apresenta sugestões de atividades e bibliografias complementares de modo a possibilitar a ampliação da temática estudada.

\begin{tabular}{|l|l|l|l|l|}
\hline & Ótimo & Bom & Suficiente & Não \\
\hline
\end{tabular}

17. O livro apresenta linguagem adequada ao nível dos estudantes do ensino médio.

\begin{tabular}{|c|c|c|c|}
\hline Ótimo & Bom & Suficiente & Nร̃ต \\
\hline
\end{tabular}

\section{COMPONENTE: CONJUNTO GRÁFICO.}

\section{Critério: Editoração e aspectos visuais}

18. A apresentação e organização gráfica devem ser harmônicas e claras, com uma iconografia nítida e adequada a escolaridade a qual se destina o livro. O sumário deve refletir a organização e formatação da obra, de modo, a facilitar a consulta da mesma.

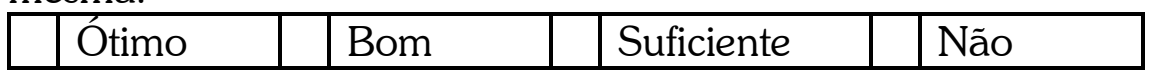

19. Os textos devem espelhar ordem, apresentar continuidade e clareza, bem como no caso de textos longos, recursos de descanso. Também não devem conter erros de impressão e revisão. As ilustrações devem obedecer às convenções propicias, por exemplo, legendadas, com títulos, fontes etc.

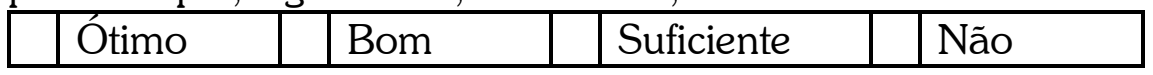

\section{Critério: Imagens e aspectos visuais.}


20. O livro apresenta imagens que possibilitem uma problematização dos conceitos filosóficos; que sejam de fácil compreensão, convidando a pensar e despertando a curiosidade e a motivação.

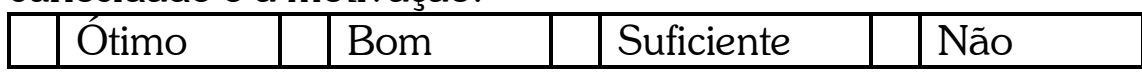

21. O livro apresenta as imagens como recurso intrínseco para a compreensão do texto utilizando-a de forma educativa, não como mera ilustração.

\begin{tabular}{|c|c|c|c|}
\hline Ótimo & Bom & Suficiente & Não \\
\hline
\end{tabular}

\section{Apresentação e discussão dos resultados}

\section{Tabela}

Análise dos livros didáticos

Componentes e indicadores

\begin{tabular}{|c|c|}
\hline & Ótimo \\
\hline Criterios: & Bom \\
\hline
\end{tabular}

\begin{tabular}{|c|c|c|c|c|c|c|c|c|c|}
\hline 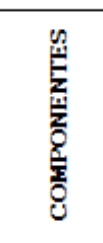 & 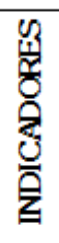 & $\begin{array}{c}\text { Filosofando } \\
\text { Introdução } \\
\text { à filosofia } \\
\text { (ARANHA, } \\
\text { 2003). }\end{array}$ & $\begin{array}{l}\text { Filosofia: } \\
\text { ensino } \\
\text { médio } \\
\text { (CHAUf, } \\
\text { 2005) }\end{array}$ & $\begin{array}{c}\text { Para } \\
\text { Filosofar } \\
\text { (CORDI, } \\
\text { 2007). }\end{array}$ & $\begin{array}{c}\text { Um outro } \\
\text { olhar: } \\
\text { filosofia } \\
\text { (SOUZA, } \\
\text { 1995) }\end{array}$ & $\begin{array}{l}\text { Pensando } \\
\text { Melhor: } \\
\text { iniciaçāo ao } \\
\text { filosofar } \\
\text { (SÁTIRO, } \\
\text { 2003) }\end{array}$ & $\begin{array}{c}\text { Filosofia } \\
\text { (SEVERINO, } \\
\text { 2007). }\end{array}$ & $\begin{array}{c}\text { Fundamentos } \\
\text { da filosofia. } \\
\text { (COTRIM, } \\
\text { 2006). }\end{array}$ & $\begin{array}{c}\text { Vivendo a } \\
\text { Filosofia } \\
\text { (CHALITA, } \\
\text { 2009). }\end{array}$ \\
\hline \multirow{11}{*}{ 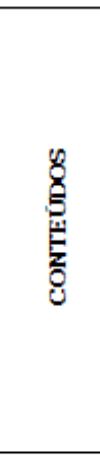 } & 1 & & & & & & & & \\
\hline & 2 & & & & & & & & \\
\hline & 3 & & & & & & & & \\
\hline & 4 & & & & & & & & \\
\hline & 5 & & & & & & & & \\
\hline & 6 & & & & & & & & \\
\hline & 7 & & & & & & & & \\
\hline & 8 & & & & & & & & \\
\hline & 9 & & & & & & & & \\
\hline & 10 & & & & & & & & \\
\hline & 11 & & & & & & & & \\
\hline \multirow{6}{*}{ 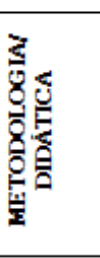 } & 12 & & & & & & & & \\
\hline & 13 & & & & & & & & \\
\hline & 14 & & & & & & & & \\
\hline & 15 & & & & & & & & \\
\hline & 16 & & & & & & & & \\
\hline & 17 & & & & & & & & \\
\hline \multirow{4}{*}{ 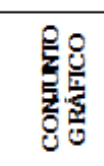 } & 18 & & & & & & & & \\
\hline & 19 & & & & & & & & \\
\hline & 20 & & & & & & & & \\
\hline & 21 & & & & & & & & \\
\hline
\end{tabular}


A tabela acima mostra a avaliação dos componentes: Conteúdos (1-11), Metodologia/didática (12-17) e Conjunto Gráfico (18-21). Dentro desses três componentes encontram-se 21 indicadores que foram avaliados pelos critérios: Ótimo, Bom, Suficiente e Não.

\section{Os componentes e indicadores}

Na compilação dos dados, por meio da aplicação do instrumento avaliativo, para se obter a porcentagem referente a cada componente levou-se em conta a quantidade de indicadores presentes em cada componente e o universo total de livros avaliados. A quantidade de indicadores (21) foi multiplicada pela quantidade de livros (8), totalizando 168 indicadores. Em seguida, calculou-se a porcentagem correspondente a cada indicador.

No componente "conteúdo", da totalidade dos indicadores dos livros, 13,6\% foi "não" e 11,3\% "suficiente". No componente "metodologia/didática", 7,1\% dos indicadores recebeu "não" e $12,5 \%$ "suficiente". No componente "conjunto gráfico", $12,5 \%$ foi "não". Percebe-se, dessa forma, que $24,9 \%$ dos indicadores do componente "conteúdo", 19,6\% dos de "metodologia/didática" e 12,5\% do "conjunto gráfico" apresentaram avaliação desfavorável.

Quanto aos indicadores, a interdisciplinaridade recebeu "não" em 4 livros (50\%) e "suficiente" em 1 livro (12,5\%), tendo avaliação desfavorável em 5 livros $(62,5 \%)$. Este indicador apresentou-se como o mais limitado, o que caracteriza a importante dificuldade observada nos livros em apresentar essa dimensão do conteúdo.

Sendo o livro didático um dos principais instrumentos de ensino, ressalta-se a fundamental importância da presença da interdisciplinaridade. O livro deve apresentar uma perspectiva interdisciplinar, relacionando integralmente os conteúdos de duas ou mais disciplinas, possibilitando uma visão de conjunto.

No indicador "léxico de filosofia", "não" correspondeu a 3 livros (37,5\%). Em um livro didático de filosofia, um léxico explicativo de termos e conceitos é essencial, uma vez que, sem a perfeita compreensão dos mesmos, o conteúdo filosófico torna-se de difícil acesso. É necessária uma noção bem clara do 
significado e aplicação de cada conceito, antes de iniciar o estudo de conteúdos nos quais tais conceitos se fazem presentes.

No indicador "história da filosofia", 2 livros (25\%) receberam "não". Embora o ensino de filosofia não deva deter-se única e exclusivamente à história da filosofia, sem esta, tal ensino não é possível.

No indicador "atividades que favorecem o debate e a argumentação sobre textos filosóficos", 1 livro recebeu "suficiente" (12,5\%). Esta habilidade deve ser contemplada pelos didáticos de filosofia, uma vez que é apontada pelos documentos que asseguram o ensino da filosofia como uma das competências a serem desenvolvidas.

No indicador "exercícios que contemplem a produção de textos filosóficos", 1 livro (12,5\%) foi avaliado como "não" e 2 livros (25\%) como "suficiente". No total, 3 livros $(37,5 \%)$ foram avaliados de forma desfavorável. Esta competência é defendida pelas Orientações Curriculares Nacionais-OCN, conforme citado acima.

No indicador "relação conteúdo filosófico x senso comum", "não" correspondeu a 1 livro $(12,5 \%)$ e "suficiente" a 3 livros (37,5\%), totalizando 4 livros (50\%). A deficiência neste quesito é preocupante, já que é o ponto de partida de todo filosofar. $\mathrm{O}$ ato de filosofar é um contínuo exercício que vai do senso comum ao filosófico e, por sua vez, volta ao senso comum. Esta relação é imprescindível, sem ela o estudo da filosofia é prejudicado.

O indicador "perspectiva filosófica" apresentou-se como "suficiente" em 3 livros (37,5\%). O livro deve deixar clara a perspectiva filosófica adotada pelo autor, ressaltando que existem outras perspectivas e o modo como elas se relacionam.

\section{Os livros}

Apresentam-se agora os resultados referentes primeiramente ao livro intitulado: "Filosofando - Introdução à filosofia", das autoras Maria Aranha e Maria Helena Martins. O livro não apresentou sérias limitações que comprometam seu desempenho no ensino médio e foi considerado mais limitado apenas em dois indicadores, "interdisciplinaridade" e "relação entre conteúdo filosófico e senso comum", por isso podemos dizer que somente $9,52 \%$ do livro não foi considerado 
como bom ou ótimo, tendo em vista que 2 indicadores do livro foram considerados como Suficiente.

Já no livro "Filosofia: ensino médio", da autora Marilena Chauí, encontrou-se maiores limitações em relação à ausência de vários conteúdos, quando se observou a avaliação "não" em relação à presença de textos clássicos da história da filosofia e em relação à presença de um léxico dos principais conceitos filosóficos. Também em relação à metodologia utilizada no livro, constatou-se a ausência de "exercícios que contemplem a produção de textos filosóficos" e de "atividades e exercícios que favoreçam o debate e a argumentação sobre os textos, temas e problemas filosóficos abordados", com isso quatro indicadores (19\%) deste livro foram avaliados como "não", ou seja, esse percentual indica que um quinto do livro não atende, de forma mínima, os indicadores da pesquisa. Além disso, a pesquisa ainda mostra que mais dois indicadores $(9,52 \%)$ presentes nos componentes conteúdo e metodologia foram avaliados como "suficiente". Se somarmos esses percentuais, chegamos ao resultado de $28,52 \%$, ou seja, mais de um quarto dos livros apresenta aspectos que necessitam serem melhorados. Podemos considerar este como um dos livros mais deficientes de toda a pesquisa, apresentando carências de conteúdo e metodologia.

Um livro que apresentou um número menor de limitações, apresentando problemas apenas na parte dos conteúdos, foi o livro Para Filosofar. Observou-se que dois indicadores $(9,52 \%)$ do livro apresentaram avaliação "não", correspondendo aos indicadores relativos à presença de todos os períodos da história da filosofia e a apresentação de uma perspectiva interdisciplinar.

O livro Um outro olhar apresentou-se de forma crítica somente no indicador que se refere à interdisciplinaridade, sendo reprovado totalmente nesse indicador. Assim, pode-se dizer que 9,52\% deste livro não atende o desejado. $\mathrm{O}$ livro também mostrou limitações, com avaliação "suficiente", no indicador que estabelece a presença de exercícios que contemplem a produção de textos filosóficos.

O livro Pensando melhor foi um dos mais problemáticos, 28,56\% do livro não é bom, podemos especificar mais ainda esses números dizendo o seguinte: 
14,28\% do livro, principalmente quando nos referimos à área de Conteúdos, se encontra em estado crítico, a obra não contempla vários conteúdos e temáticas da filosofia, observa-se isso a partir das avaliações "não" atribuídas a três indicadores, que se referem a "presença de todos os períodos da história da filosofia", a presença de "relações de influência, continuidade, diferença e descontinuidade entre as perspectivas filosóficas ao longo da história", e a presença "de um léxico explicativo dos principais conceitos abordados". Também na área de conteúdos, os indicadores dois, três e onze (14,28\%) receberam a avaliação "suficiente", o que indica a necessidade de melhorá-los. Constata-se, assim, que as limitações deste livro se referem exclusivamente ao componente Conteúdo. Pode-se dizer então que seis indicadores, correspondentes a 50,45\% dos conteúdos deste livro não estão em um nível bom, precisando ser melhorados e aprimorados.

O livro que apresentou o maior índice de indicadores negativos foi o livro "Filosofia", do autor Antônio Joaquim Severino, que mostrou um percentual crítico, avaliação "não", em cinco indicadores (23,80\%). Dos cinco indicadores reprovados, quatro correspondem à totalidade do componente Conjunto gráfico, em que se constatou a falta de imagens, de uma iconografia, o livro também não apresentou clareza na organização dos textos, não havendo continuidade entre os textos $e$ as temáticas. O outro indicador avaliado como "não" se refere à interdisciplinaridade. Também se observou a presença de três indicadores $(14,28 \%)$ com avaliação "suficiente", sendo um no componente conteúdo e dois em metodologia/didática. Quando somadas as avaliações "não" $(23,80 \%)$ com a avaliação "suficiente" (14,28\%), chega-se a um total de 38,08\% (oito indicadores), que correspondem a aspectos do livro que devem ser revistos e melhorados.

O livro "Fundamentos da filosofia", de Gilberto Cotrim, apresentou baixos índices negativos, em todo o livro o percentual crítico, que é analisado pela reprovação total do indicador, foi de um indicador $(4,76 \%)$, e se refere à presença de "um léxico explicativo dos principais conceitos abordados". Além deste, recebeu avaliação "suficiente" os indicadores onze, do componente Conteúdo e os indicadores doze e dezesseis do componente Metodologia/didática, que somam um resultado de $(14,28 \%)$ dos indicadores. Na soma dos dois percentuais chegamos a 
$19,04 \%$, um índice do livro que se pode dizer que precisa ser revisto, melhorado e aperfeiçoado.

Por fim, outro livro que não teve um bom desempenho foi o de Gabriel Chalita intitulado Vivendo a filosofia, que apresentou avaliação "não" em três indicadores (14,28\%), sendo dois do componente conteúdo, indicadores relativos à presença dos "principais problemas filosóficos de modo a favorecer a reflexão e a compreensão de sua atualidade" e em relação à "perspectiva interdisciplinar". O outro indicador que obteve avaliação "não" está presente no componente metodologia/didática, e se refere a que "o livro proporcione a atitude crítica $e$ distanciada das idéias e valores do senso comum". Observou-se também em relação ao componente conteúdo, a avaliação "suficiente" em três indicadores (14,28\%). Somando-se os índices relativos aos indicadores com avaliação "não" e "suficiente", constatam-se seis indicadores (28,56\%) que necessitam ser melhorados no livro; ressalta-se que, destes seis indicadores, cinco estão presentes no componente Conteúdo, representando neste componente um percentual de $42,34 \%$.

\section{Considerações finais}

Verificou-se nos livros um grande número de indicadores "bom" e "ótimo", configurando-se assim, um quadro geral positivo. Entretanto, foi possível observar componentes $e$ indicadores com problemas mais evidentes, bem como alguns livros com problemas pontuais em alguns componentes e indicadores. A pesquisa não pretendeu aprovar ou reprovar os livros em sua totalidade, mas tão somente apontar limitações existentes nas obras. Todavia, ressalta-se que o livro "Filosofando", das autoras Maria Lúcia de Arruda Aranha e Maria Helena Pires Martins obteve avaliação geral satisfatória, não recebendo "não" em nenhum de seus indicadores. Espera-se que os resultados da pesquisa possam contribuir para a escolha dos usuários - instituições de ensino, alunos e leitores em geral; e de indicação para editores $e$ autores, quando de eventuais aperfeiçoamentos ou reformulações das obras, com vistas à melhoria do ensino de filosofia. 


\section{REFERÊNCIAS}

ARANHA, Maria Lúcia de A.; MARTINS, Maria Helena P. Filosofando: Introdução à filosofia. $3^{a}$ Edição. São Paulo: Moderna, 2003. ISBN 85-1603-746-0

BRASIL. Parâmetros Curriculares nacionais. ensino médio. V. IV, Ciências Humanas e suas Tecnologias, Brasília, DF: Ministério da Educação/Secretaria de Educação Média e Tecnológica, 1999.

BRASIL. Ministério da Educação. Guia de livros didáticos PNLD 2008: História / Ministério da Educação. — Brasília: MEC, 2007.

BRASIL, Ministério da Educação. Secretaria de Educação Média e Tecnológica. Conhecimentos de filosofia. In. Parâmetros Curriculares Nacionais: ensino médio. Brasília: MEC/SEMT, Cento Gráfico, 1999.

BRASIL. Ministério da Educação. Secretaria de Educação Média e Tecnológica. Organização Curricular Nacional. Brasília: MEC/SEMT, Cento Gráfico, 2002.

BRASIL. Ministério da Educação. Secretaria de Educação Média e Tecnológica. Parâmetros Curriculares Nacionais +. Brasília: MEC/SEMT, Cento Gráfico, 2006.

CHALITA, Gabriel. Vivendo a Filosofia. $3^{\mathrm{a}}$ Ed. São Paulo: Ática, 2009. ISBN: 978850810566-3.

CHAUI, Marilena. Filosofia: ensino médio, volume único. São Paulo: Ática, 2005. Série Brasil. ISBN 85-08-09827-8.

CORDI, C. et al. Para filosofar. 5 ed. São Paulo: Scipione, 2007. ISBN 978852626704-6.

CORNELLI, Gabriele. A lição dos clássicos: algumas anotações sobre a história da filosofia na sala de aula. In. GALLO, Silvio; DANELON, Márcio; CORNELLI, Gabriele. (organizador). Ensino de filosofia: teoria e prática. Ijuí: Ed. UNIJUÍ, 2004. COTRIM, Gilberto. Fundamentos da Filosofia: História e grandes temas. $16^{\mathrm{a}} \mathrm{Ed}$. São Paulo: Saraiva, 2006. ISBN. 978-85-02-05787-6

GALLO, Silvio; KOHAN, Walter (orgs.). Filosofia no Ensino Médio. Petrópolis: Vozes, 2000. 
GALLO, Silvio; KOHAN, Walter O. Crítica de alguns lugares-comuns ao se pensar a filosofia no ensino médio. In. GALLO, Silvio; KOHAN, Walter O. (organizadores). Filosofia no ensino médio. Petrópolis: Vozes, 2000.

GALLO, Silvio. O problema e a experiência do pensamento: implicações para o ensino da filosofia. In. BORBA, Siomara.; KOHAN, Walter O. Filosofia, aprendizagem, experiência. Belo Horizonte: Autêntica Editora, 2008.

KOHAN, Walter O. (org.). Filosofia: caminhos para o seu sentido. Rio de Janeiro: DP\&A, 2004.

MARCONDES, Danilo. É possível ensinar a filosofia. E, se possível, como? In.

SÁTIRO, Angélica; WUENSCH, Ana Miriam. Pensando Melhor: iniciação ao filosofar. $4^{a}$ edição reformulada. São Paulo: Saraiva, 2003. ISBN 85-0204-458-3, SEVERINO, Antonio Joaquim. Filosofia. $2^{\text {a }}$ Ed. São Paulo: Cortez, 2007. ISBN: 978-85-249-0410-3

SOUZA, Sonia Maria R. de. Um outro olhar: filosofia. São Paulo: FTD, 1995. ISBN 85-322-2439-3.

SOUZA, Sonia Maria R. A filosofia no ensino médio: uma (re) leitura a partir dos PCNs. In. GALLO, Silvio; DANELON, Marcio; CORNELLI, Gabriele. (organizadores). Ensino de filosofia: teoria e prática. Ijuí: Ed. UNIJUÍ, 2004. SPOSITO, M. E. B.; LUCA, T. R. Avaliação de livros didáticos de geografia e história: relato de experiências. In. BARBOSA, R. L. L. (org.). Trajetórias e perspectivas da formação de educadores. São Paulo: Editora UNESP, 2004. 